\title{
Compreendendo o Trabalho da Costureira: um Enfoque para a Postura Sentada
}

Dagmar Ambrosi ${ }^{1}$

Maria de Fátima Ferreira Queiroz ${ }^{2}$

\section{Understanding the Job of a Dressmaker: with Emphasis on the Sitting Posture}

'Ex-aluna da Faculdade de Educação Física e Fisioterapia-Curso de Fisioterapia da Universidade Metodista de São Paulo.

${ }^{2}$ Faculdade de Educação Física e Fisioterapia - Curso de Fisioterapia da Universidade Metodista de São Paulo; SMS-Coordenação de Vigilância em Saúde (COVISA), Prefeitura do Município de São Paulo.
As trabalhadoras da indústria de confecção, principalmente no setor de costura, desenvolvem suas tarefas na postura sentada e a operação de máquinas de costura requer o uso repetitivo e coordenado do tronco, extremidades superiores e inferiores das operárias que trabalham em postura sentada prolongada. Visando verificar os desconfortos presentes no desenvolvimento do trabalho da costureira, foi realizada uma análise ergonômica em uma indústria da confecção na cidade de Santo André, Brasil. O estudo contou com observação da realização do trabalho real, aplicação de um questionário a fim de colher dados sobre o perfil dos trabalhadoras, conhecer suas relações de trabalho e sua situação de saúde.

Palavras-chave: saúde do trabalhador, ergonomia, indústria da confecção, costureiras.

The employees at a confection industry, especially the sewing section, do their jobs in a sitting posture and to operate a sewing machine requires the repetitive use and coordination of the upper part of the body, superior and inferior extremities of the employees that work in a prolonged sitting posture. Aiming at verifying the discomforts present while the dressmaker is performing her job, an ergonomical analysis was performed in a confection industry in the city of Santo André, Brazil. The study was accomplished by observing the performance on the job. A questionnaire was applied to collect data about the profile of the employees and to know their work relationships and health situation.

Keywords: worker's health, ergonomic, confection industry, dressmaker. 


\section{Introduc̣ão}

As empresas industriais que trabalham na manufatura de peças de vestuário, produtos em couro, sapatos etc. empregam um grande número de homens e mulheres que trabaIham na operação de máquinas de costura.

Tradicionalmente, alguns setores da indústria são ocupados por uma boa porcentagem de mulheres. Este é o caso das indústrias de vestuário e calçados (65\%), farmacêutica e veterinária $(54 \%)$, de fumo (53\%), perfumaria e sabonete (33\%) (Ribeiro et al. 1984). A incorporação do trabalho da muIher na indústria é bem maior nas regiões desenvolvidas do Brasil, alcançando em São Paulo o dobro da média nacional, isto é, em cada cem mulheres que trabalham, trinta estão na indústria (Ribeiro et al. 1984).

A operação de máquinas de costura requer o uso repetitivo e coordenado do tron$\mathrm{co}$, extremidades superiores e inferiores das operárias que trabalham em postura sentada prolongada (Nag et al. 1992).

A postura de trabalho representa principalmente um meio para desempenhar a atividade. As posturas e os movimentos de trabalho são determinados pelo espaço físico no qual o corpo e, principalmente, seus segmentos estão localizados, pelas características das informações a serem captadas e pelas ações a serem desempenhadas no espaço (Barreira, 1989, 1994; Laville, 1977).

As trabalhadoras da indústria de confecção, principalmente no setor de costura, desenvolvem suas tarefas na postura sentada. Para costurar, muitas atividades manuais são executadas e estas exigem um acompanhamento visual, isso significa que o tronco e a cabeça ficam inclinados para frente. $O$ pescoço e as costas ficam submetidos a tensões mantidas por longos períodos, o que poderá acarretar dores. O dorso pode ser submetido também a tensões, quando for necessário girar o corpo, estando o trabalhador em um assento fixo (Dul \& Weerdmeester, 1995).

A coluna vertebral pode sofrer uma série de alterações nas suas estruturas constituintes em virtude de posturas e atividades motoras inadequadas adotadas pelo trabalhador diante da exigência de sua tarefa
(Calliet, 1975; Knoplich, 1983, apud Barreira). De acordo com Grandjean (1998) e Mont'alvão (1994), na postura sentada ocorre um afrouxamento dos músculos abdominais que será prejudicial aos órgãos de digestão e respiração.

Em um estudo, Nag et al. (1992) relatam que um trabalho de costura por longo período tem uma carga cumulativa nas estruturas músculo-esqueléticas, incluindo a coluna vertebral e refletindo na forma de grande prevalência de desconforto e dor em partes diferentes do corpo. Além dos problemas com - disco intervertebral, o estudo feito pelos autores evidenciou que $68 \%$ das cento e sete mulheres estudadas reclamavam de dores nas costas (lombalgias persistentes e insuportáveis). Outras 35\% reclamavam de dores de cabeça, desconforto nos músculos abdominais, esforço dos olhos e edema nos pés devido ao acúmulo de fluidos corporais.

Punnett et al. (1985) também relatam que trabalhadores em certas tarefas de costura, especialmente aqueles que colocam o forro dentro das jaquetas, têm uma maior prevalência de dores persistentes do que os trabaIhadores que realizam outras tarefas. Kaergaard et al. (2000) citam que o trabaIho na indústria da confecção envolve monotonia, tarefas altamente repetitivas realizadas em uma postura sentada com a região superior das costas curvada e a cabeça dirigida para a máquina de costura e, além disso, exige um alto grau de concentração e acurácia.

\section{Objetivo}

Este trabalho tem como objetivo geral verificar os desconfortos que o trabalho em postura sentada pode trazer às trabalhadoras na indústria da confecção, com enfoque no trabalho das costureiras. E como objetivo específico, o de identificar as cargas de trabalho e os fatores de riscos presentes na postura sentada mantida por longos períodos, que podem levar ao acometimento de membros superiores, troncos e membros inferiores.

\section{Materiais e métodos}

Trata-se de uma pesquisa descritiva em que - método tem como base a análise ergo- 
nômica do trabalho. A ergonomia estuda vários aspectos do trabalho, desde questões de posturas e movimentos corporais a fatores ambientais que interferem nas condições de trabalho e congrega vários conhecimentos relevantes de diversas áreas do conhecimento humano (Queiroz, 1998).

A ergonomia é definida como o estudo da adaptação do trabalho ao ser humano, entendendo o trabalho com uma concepção mais ampla, a qual engloba o estudo de toda a situação em que ocorre o relacionamento entre o ser humano e seu trabalho (lida, 1998).

Foi realizada análise ergonômica do trabalho na postura sentada em uma indústria de confecção do município de Santo André, Brasil. O posto estudado se incluía na etapa de colocação de elástico nas pernas das calcinhas. A máquina utilizada para esta atividade é a de "três pontos".

Foi observada a realização da tarefa real, enfocando as posturas, os movimentos corporais e os fatores ambientais que interferem diretamente no trabalho.

Foram também utilizados um roteiro de observação, traduzido e adaptado do Worksafe Austrália (1992) e de McAtamney e Corlett (1999) por Maciel (1998), utilizado por Queiróz (1998), e um questionário elaborado a partir de um conhecimento prévio. O questionário foi respondido por nove costureiras a fim de colher dados sobre o perfil das trabalhadoras, conhecer suas relações de trabalho e sua situação de saúde.

\section{Resultados}

\section{Caracterização da Indústria}

O estudo foi realizado em uma indústria de pequeno porte de confecção de calcinhas e sutiãs situada na região de Santo André desde 1992, e desde 1999 encontra-se nas instalações atuais.

Hoje a indústria está com produção fixa e abarca uma pequena fatia do mercado de consumo comum das indústrias de pequeno e médio porte desse tipo de atividade.

Na indústria, as trabalhadoras nos postos similares ao analisado são oito, com idade entre 25 e 39 anos. O tempo de trabalho das trabalhadoras está entre um e três anos.
Apenas uma trabalhadora está há quatro anos na indústria.

\section{O Processo de Produção}

A indústria é composta por seis setores: (1) administrativo e financeiro (inclui compras e vendas), (2) corte, (3) costura, (4) controle de qualidade, (5) expedição e (6) limpeza.

No setor de costura, são realizadas as tarefas de costurar as peças de diferentes tecidos (malha, lycra), operando máquinas do tipo goloneira, zig zag, overloque, traveti. Cada costureira trabalha na sua máquina e não há rodízio. Duas trabalhadoras, das trinta que trabalham nesse setor, têm as seguintes tarefas: pegam linhas, levam as peças para o controle de qualidade e "fazem o que for preciso" para que as costureiras não levantem durante o trabalho. Assim, o trabalho das costureiras é realizado na postura sentada durante toda a jornada de trabalho.

A organização da produção ocorre da seguinte maneira: quando o tecido chega na fábrica, é aberto na mesa de corte por doze horas para evitar que encolha, procedimento denominado enfestamento. Após, o tecido é riscado e cortado e a próxima etapa é o processo de costura, sendo a "produção" propriamente dita. As costureiras das máquinas overloque começam a trabalhar na montagem das peças.

Após a montagem, a peça vai para as elastiqueiras, que trabalham nas máquinas três pontos, para serem colocados elásticos nas pernas e na cintura das calcinhas já montadas. Algumas peças precisam passar na máquina traveti para serem reforçadas (por exemplo, sutiã). Colocado o elástico, as peças são encaminhadas para o controle de qualidade e só então são encaminhadas para o setor de expedição e embaladas individualmente.

\section{A Organização do Trabalho}

A direção da indústria está representada pelos dois sócios. Os trabalhadores somam quarenta e três funcionários com faixa etária entre 17 e 48 anos, sendo dois trabalhadores do sexo masculino. Pode-se observar que, seguindo uma característica da indústria de confecção, prevalece a presença do sexo feminino no processo de produção. 
A produção conta com quinze modelos de calcinha de algodão (liso, bordado e rendado) e cotton. A produção é de aproximadamente 1800 peças/dia, ou seja, uma produção de $36 \mathrm{mil}$ peças/mês. O turno de trabalho é das $7 \mathrm{~h}$ às $16 \mathrm{~h} 48 \mathrm{~min}$, de segundafeira à sexta-feira. Existem três pausas formais durante a jornada: café da manhã (das $9 \mathrm{~h}$ às $9 \mathrm{~h} 10 \mathrm{~min}$ ), almoço (das $12 \mathrm{~h}$ às $13 \mathrm{~h}$ ) e café da tarde (das $15 \mathrm{~h}$ às $15 \mathrm{~h} 10 \mathrm{~min}$ ).

O questionário respondido pelas trabalhadoras mostrou que todas acreditam que a taxa de produção está dentro de suas capacidades, que elas têm controle sobre o ritmo de trabalho e que a carga de trabalho é determinada pelos pedidos, sendo que, quando há menos pedido, o dia fica mais folgado e, quando há mais pedidos, o dia fica mais puxado.

\section{- Posto Estudado}

\section{Aspectos Físicos e Ambiente de Trabalho}

O posto está localizado em um espaço amplo, onde as máquinas estão dispostas uma atrás da outra, formando duas fileiras. O piso ao redor da máquina é de cerâmica, ao que nosso ver não ocasiona nenhum risco a saúde das trabalhadoras. A iluminação do ambiente é realizada de forma artificial e natural. Segundo as respostas que as trabalhadoras deram ao questionário, cinco estão satisfeitas com a iluminação e quatro concordam que o ambiente é escuro.

O ruído das máquinas é intenso e contínuo e em nenhum momento cessam, mas, de acordo com a resposta que as trabalhadoras deram ao questionário, seis consideram que o ruído não incomoda e três, que incomoda. Ao nosso ver, o ruído causa desconforto acústico.

A ventilação é realizada de forma artificial e natural. A artificial é realizada por três ventiladores, que são ligados somente em tempo de muito calor, e a natural circula por sete janelas. De acordo com a resposta das trabalhadoras, para três delas a ventilação é suficiente e para seis o ambiente é muito quente.

\section{Descrição da Atividade e das Tarefas}

A máquina utilizada para realização da tarefa é da marca Singer e a atividade da costureira pode ser dividida em cinco tarefas principais:

(1) Controle do funcionamento da máquina;

(2) Colocação da calcinha já montada embaixo do calcador;

(3) Costura do elástico nas pernas da calcinha;

(4) Retirada das rebarbas maiores e a troca de agulhas quebradas;

(5) Limpeza da máquina.

(1) Controle do funcionamento da máquina: A máquina de costura é acionada, ou seja, colocada em movimento através de um pedal. A trabalhadora aciona o pedal e este aciona a máquina. Intercorrências podem acontecer como, por exemplo, a quebra do motor, o que impedirá que a máquina funcione. Esse é um tipo de ocorrência relatada pela trabalhadora e que, durante nossa observação, ocorreu.

(2) Colocação da calcinha já montada embaixo do calcador: Para realizar esta tarefa, a trabalhadora empurra uma alavanca que fica do lado direito da máquina. $O$ ato de empurrar essa alavanca é realizado pelo joelho direito. Assim que a alavanca é empurrada, o calcador levanta e a calcinha é colocada embaixo dele.

(3) Costura do elástico nas pernas da calcinha: Assim que a calcinha é colocada embaixo do calcador, é acionada a máquina, que irá costurar o elástico. A trabalhadora regula a tensão do elástico, que dará o tamanho da peça, para saber se está de acordo com o tamanho da calcinha. Na mesa da máquina existe uma régua, com a qual a trabalhadora mede a calcinha.

(4) Retirada das rebarbas maiores e a troca de agulhas quebradas: Para realizar esta tarefa é necessário o uso de uma tesoura, que servirá para cortar as rebarbas. É preciso que se levante o calcador, retire a agulha quebrada, solte um parafuso com uma chave de fenda e coloque uma agulha nova, apertando novamente o parafuso, e, por fim, abaixe o calcador.

(5) Limpeza da máquina: Para limpar a máquina é necessário o uso de um pincel, que irá tirar os restos de linhas que ficam na máquina. A limpeza é feita no final de cada lote de calcinhas de cores diferentes e quando termina a jornada de trabalho. 


\section{Posturas Adotadas}

Através das observações realizadas, verificou-se que a trabalhadora mantém uma postura sentada por toda jornada de trabalho. As posturas observadas estão detalhadas a seguir:

1. Para ativar o pedal que acionará o motor e colocará a máquina em movimento, a costureira realiza plantiflexão e dorsiflexão com o pé direito. $O$ não relaxamento dos plantiflexores e dorsiflexores levará a uma diminuição da circulação devido a uma constante contração desses músculos e à compressão dos vasos sanguíneos, o que acarretará dores intensas na região do tríceps sural.

2. Para elevar o calcador, a costureira faz abdução da perna direita empurrando uma alavanca com o joelho direito. A repetição desse movimento poderá causar dores na região de abdutores do quadril e dores na região lateral do joelho direito.

3. Para costurar o elástico na calcinha, a costureira faz flexão de cotovelo, flexão e desvio ulnar do punho e os dedos das mãos ficam em semiflexão e dando apoio para segurar o tecido a fim de não deixar que ocorram erros na costura. Como essa movimentação é repetida em um ciclo curto de 30 segundos e utiliza sempre os mesmos músculos, poderá levar à ocorrência de dores e até mesmo gerar uma inflamação nos tendões e nas bursas das articulações envolvidas.

4. A costureira tem que manter uma protusão da cabeça, a flexão da coluna cervical e lombar, para ficar atenta ao trabalho, pois qualquer distração poderá acarretar em uma costura errada ou até mesmo em um acidente como, por exemplo, furar o dedo com a agulha da máquina.

5. Os membros inferiores (joelhos e quadris) devem permanecer flexionados para dar equilibrio, servir de apoio e distribuir a carga da postura sentada. Porém, essa posição mantida por muito tempo diminuirá a circulação, o que levará a uma diminuição do aporte sanguíneo para o músculo, podendo ocasionar fadiga e gerando dores nessa região.

As posturas apresentadas são mantidas por longos períodos durante a jornada. Isso acarreta dores difusas pelo corpo (pelo fato de haver uma diminuição da circulação, di- minuindo o aporte de nutrientes para o sangue e conseqüentemente levando a uma fadiga dos músculos) nas regiões dos membros inferiores (tríceps sural), da coluna lombar, da coluna cervical (trapézio) e dos membros superiores, como relata a própria costureira. $E$, além de serem mantidos por longos períodos, os movimentos são repetidos a cada ciclo de trabalho.

Quanto à manutenção da postura sentada, as trabalhadoras relatam que não podem variar a postura de trabalho, mas que $o$ espaço permite liberdade de movimentos.

Uma questão observada que promove uma postura desconfortável é a cadeira de trabalho. Em relação à cadeira, oito das trabalhadoras entrevistadas relatam que a cadeira é desconfortável e só uma relatou que a cadeira é confortável. A cadeira não é ajustável, pois é de tipo apoio de quatro pés.

Ainda sobre a cadeira, as trabalhadoras dizem que o encosto realmente não serve de apoio para as costas, que é preciso colocar almofadas para diminuir o espaço entre as costas e a cadeira, melhorando o apoio da coluna lombar.

Nossa observação demonstrou que os braços, o pescoço e o corpo não ficam confortáveis durante o trabalho, e o problema está relacionado ao mobiliário e aos movimentos repetidos.

\section{Ritmo e Repetitividade de Trabalho}

Para avaliar a repetitividade da atividade, é necessário determinar o ciclo de trabalho. Se o trabalho tem uma seqüência de fases repetidas dentro de um ciclo de trabalho, essa seqüência é definida como um "ciclo fundamental" (Silverstein et al., 1987). A partir do conhecimento da extensão do ciclo, a repetitividade pode ser definida como alta, quando a extensão do ciclo é menor que 30 segundos ou quando mais do que $50 \%$ do tempo do ciclo envolve o mesmo tipo de ciclo fundamental de trabalho (Silverstein et al., 1986, 1987; Ahonen et al., 1989; Kilbom, 1994.

Em concordância com a definição de repetitividade, pode-se considerar o trabalho analisado como sendo repetitivo, pois a trabalhadora usa os mesmos grupos mus- 
culares para realização da tarefa durante toda a jornada de trabalho e o ciclo de trabalho é equivalente a 30 segundos para costurar 0 elástico em uma calcinha.

\section{A Situação de Saúde dos Trabalha- dores}

O questionário constava de um mapa de corpo (body map), no qual foi pedido que as trabalhadoras entrevistadas apontassem no mapa a região onde sentiam dores. As re- giões do corpo citadas pelas trabalhadoras são apresentadas na Tabela 1 .

Pode-se observar na Tabela 1 que as referências de dores foram percentualmente maiores para a região cervical e a panturrilha, seguidas da coluna lombar e dos ombros. Região cervical e panturrilhas somam $54,6 \%$ das citações. Essas são as regiões que realmente estão sob tensão de acordo com nossa observação e a literatura referenciada.

Tabela 1 Distribuição das citações das trabalhadoras segundo as dores nas regiões do corpo.

\begin{tabular}{lcc}
\hline Regiões do corpo & № de apontamentos de dor & $\%$ \\
\hline Região cervical (musc. trapézio) & 6 & 27,3 \\
Ombros & 4 & 18,2 \\
Braço e antebraço & 1 & 4,5 \\
Dedos das mãos & 1 & 4,5 \\
Coluna Lombar & 4 & 18,2 \\
Panturrilha (tríceps sural) & 6 & 27,3 \\
\hline Total & $\mathbf{2 2}$ & $\mathbf{1 0 0 , 0}$ \\
\hline
\end{tabular}

Lembramos aqui que o total diz respeito ao número de citações e não ao número de trabalhadoras entrevistadas.

\section{Sugestões das Trabalhadoras}

Ao serem perguntadas se tinham sugestões para melhorar o local de trabalho, foram obtidas as seguintes respostas:

- cinco trabalhadoras responderam que dever existir mais ventiladores para amenizar a temperatura que, segundo elas, é muito quente;

- cinco trabalhadoras responderam que deveria haver mudanças nas cadeiras, pois as que estão na indústria no momento são desconfortáveis;

- duas trabalhadoras responderam que deveria haver um aumento de 10 minutos para 15 minutos no tempo para o café;

- uma trabalhadora respondeu que deveria haver mudança na iluminação; e

- uma trabalhadora não deu nenhuma sugestão.

\section{Discussão/conclusão}

Pelo trabalho observado, entende-se que as tarefas executadas não requerem um maior desenvolvimento de força muscular, mas sim de habilidade e destreza. Essas exigências estão associadas à exigência de atenção e de certo grau de concentração. Pode-se considerá-lo um trabalho monótono. A monotonia, segundo lida (1998), é a reação do organismo a um ambiente uniforme, pobre em estímulos ou com pouca variação de excitações. Ainda segundo o autor, as operações repetitivas na indústria e o tráfego rotineiro são condições próprias à monotonia. Nossas observações nos levam a concordar com as de lida (1998) no que diz respeito às condições geradoras de monotonia: a curta duração do ciclo de trabalho, períodos curtos de aprendizagem e restrições dos movimentos corporais. Ambientes ruidosos e com isolamento social (pouca possibilidade de contato com colegas de trabalho) são outros fatores que influenciam na monotonia. Nas observações do posto, pode-se constatar um ciclo de atividade curto, de 30 segundos, e restrições dos movimentos corporais determinadas, em parte, pela repetição destes.

De acordo com a observação e o conhecimento da atividade desenvolvida no posto de trabalho, a posição que o corpo precisa ado- 
tar, que no caso é a postura sentada, nunca é modificada. A trabalhadora está sempre na mesma postura, utilizando os mesmos grupos musculares e assim ocasionando dores por todo o corpo, principalmente nos membros inferiores (tríceps sural), na coluna cervical (trapézio), na coluna lombar e nos membros superiores, o que concorda com as referências de Coury (1995) para a permanência em uma postura sentada no trabalho.

Outra questão levantada pelas observações é a questão da repetitividade, que é avaliada pela seqüência de fases repetitivas dentro de um ciclo de trabalho. Essa sequiência é definida como um "ciclo fundamental" (Silverstein et al., 1987). Nossas observações concordam com as citações, pois a trabalhadora realiza suas tarefas em um ciclo menor que 30 segundos e utiliza sempre os mesmos músculos. Uma questão em discussão é: Podese aumentar tal ciclo de trabalho? Um trabaIho com movimentos repetitivos será sempre repetitivo em função do tamanho do ciclo? Talvez a questão da repetitividade esteja ligada ao processo de produção da indústria da confecção devido a alguns fatores, tais como a própria máquina de costura como um equipamento limitante, o tamanho da peça a ser confeccionada lárea pequena para se costurar), a organização do trabalho determinando o ritmo (maior ou menor demanda). Esses fatores contribuem com a dificuldade em aumentar o ciclo de trabalho. O trabalho moderno, segundo Maciel (1995), está baseado em padrões de produção e em movimentos simples que devem ser realizados muitas vezes por dia, além disso, na maioria das situações, há pouco tempo para pequenas pausas de descanso. $O$ trabalho de costura artesanal, no nosso entender, sofreu então uma transformação para um trabalho industrial com exigências de tempo e realizado em ritmo acelerado. Assim, as mudanças no trabalho das costureiras podem estar centradas nas mudanças do padrão de produção.

O que a observação nos demonstrov é que não há uma quantidade determinada de calcinhas para costurar, porém a costureira costura as calcinhas em ritmo acelerado para finalizar o pedido mais rápido e ficar satisfeita em entregar os pedidos já prontos o mais cedo possível. A maneira pela qual a trabalhadora age frente às tarefas dá a entender que ela se preocupa muito com o trabalho, sempre tentando fazê-lo "perfeito". Isso nos leva a crer que a instabilidade no emprego que predomina no Brasil, e no âmbito mundial, pode ser um fator que leve a trabalhadora a ser exigente com seu trabalho, a fazêlo de forma exemplar devido ao "medo" de perder o emprego. Por outro lado, a perfeição pode ser uma característica da trabalhadora e ela pode realmente gostar do trabalho que faz equerer fazê-lo com perfeição.

Desde os primórdios da costura, parece-nos que esta sempre foi realizada em postura sentada, uma vez que a máquina de costura fica em cima de uma mesa e a altura desta leva a trabalhadora a se sentar. Podemos entender então que quem determina a postura para costurar é o equipamento de trabalho, no caso, a máquina de costura. Com base nessa acertiva, a concepção de máquinas com design ergonômico pode auxiliar na mudança de postura, mas acreditamos que talvez continue sendo em postura sentada. Intervenções que venham a ocorrer podem ser apenas para aliviar a carga muscular e promover conforto. Porém, conforme relato das próprias costureiras, "o trabatho continuará sendo o mesmo". Portanto, no trabalho em que não pode haver nenhuma alternância da postura, somos levados a compreender por que ele se torna cansativo, pois sempre estão em tensão os mesmos grupos musculares.

Como fica difícil a costura na postura em pé, ou mesmo a alternância da postura sentada com a em pé, deveria haver mais pausas durante a jornada de trabalho. A introdução de pausas deve ser institucionalizada. Aqui entra a relação entre a introdução de pausas e a Organização do Trabalho, que é definida, segundo Hagberg et al., 1995, como o caminho em que os processos de trabalho são estruturados, distribuídos e supervisionados. A gerência tem que se apresentar flexível para compreender que as pausas promovem descansos da musculatura e conseqüentemente melhora a produtividade da trabalhadora.

Uma questão apontada pelas costureiras foi o fato de a cadeira se tornar um proble$\mathrm{ma}$, gerando assim dores no corpo, pelo seu não ajustamento e pela falta de alternância de postura. Além das cadeiras não serem reguláveis, os assentos possuem estofamentos inadequados que, com o passar do tempo, acabam deformando-se, gerando, assim, compressão das coxas e do quadril. Para di- 
minuir essa compressão, as costureiras colocam uma almofada. Assentos moldados, como é o caso do estudado, com relevos adaptados à forma do corpo (formato anatômico), são desaconselháveis, pois dificultam a mudança de posição. O mesmo acontece com estofamentos muito altos, que se comprimem quando se senta neles e que, com o uso, tendem a deforma-se, ficando aprofundados no centro. Segundo Brandimiller (1999), a colocação de almofadas é ainda pior.

Visando proporcionar conforto e descanso da musculatura no trabalho, consideramos importante citar algumas recomendações gerais que venham contribuir com a execução do trabalho das costureiras:

- Para diminuir a sobrecarga, recomendamos que haja um aumento do número de pausas, com tempos menores, e que a importância destas seja incorporado pela gerência, que veja não só um simples descanso, mas um ganho para a manutenção da saúde da trabalhadora acoplado a uma melhor produtividade.

- Para redução da sobrecarga da musculatura da coluna lombar, sugere-se trocar as cadeiras existentes hoje na indústria por cadeiras que possuam altura compatível com a estatura da trabalhadora que se sentará na cadeira; que seja giratória, eliminando esforços na coluna vertebral devido a contínuos movimentos laterais; que o estofado do assento seja de material que não deforme, evitando assim que a costureira tenha que por almofadas no assento a fim de evitar esta deformação e a compressão das coxas e do quadril, diminuindo as dores dos membros inferiores. $O$ encosto deve ser regulável para se adaptar ao corpo da trabalhadora, proporcionando proteção à região lombar e evitando a protusão da cabeça, o que diminui as dores na região cervical. Além da troca das cadeiras, deveriam ser feitos estudos posteriores, nos quais os fabricantes das máquinas de costura produzissem uma máquina que a trabalhadora pudesse alternar a postura entre sentada e em pé.

Consideramos finalmente que uso da abordagem ergonômica nos proporcionou o entendimento de que muitos dos problemas estão relacionados à organização do trabaIho (ritmo de trabalho, ausência de pausas etc.), aos aspectos físicos, ao ambiente de trabalho e às postura adotadas devido às exigências das tarefas e do mobiliário.

\section{Referências Bibliográficas}

AHONEN, M., LAUNIS, M. \& KUORINKA, T. Ergonomic Worplace Analysis. Finnish Institute of Occupational Health, 1989.

BARREIRA, T. H. C. Um Enfoque Ergonômico para as Posturas de Trabalho. Revista Brasileira de Saúde Ocupacional, 1989; 17: 61-71.

Fatores de Risco para Lesões por Esforços Repetitivos em uma Atividade Manual Repetitiva. Dissertação de Mestrado apresentada ao Instituto de Psicologia da Universidade de São Paulo. São Paulo, 1994.

BRANDIMILLER, P. A. O Corpo no TrabaIho: Guia de Conforto e Saúde para quem Trabalha em Microcomputadores. São Paulo: Editora Senac, 1999, p. 69
CAILLET, R. Tecidos Moles, Dor e Incapacidade. São Paulo: Manole, 1975.

COURY, H. G. Trabalhando Sentado Manual para Posturas Confortáveis. 2 ed. São Carlos: Ufscar, 1995.

COURY, H.G. \& RODGHER, S. Treinamentos para o Controle de Disfunções MúsculoEsqueléticas Ocupacionais: Um Instrumento Eficaz para Fisioterapia Preventiva? Revista Brasileira de Fisioterapia, 1997; 2:1: 07-17.

DUL, J. \& WEERDMEESTER, B. Ergonomia Prática. São Paulo: Edgard Blücher, 1995.

GRANDJEAN, E. Manual de Ergonomia. 4 ed. Porto Alegre: Artes Médicas Sul, 1998. 
HAGBERG, M. et al.,Work Related Musculoskeletal Disorders (WMSDS): A Reference Book for Prevention. London: Taylor \& Francis, 1995.

IIDA, I. Ergonomia: Projeto e Produção. 5 ed. São Paulo: Edgard Blücher, 1998.

KAERGAARD, A. \& ANDERSEN, J. H. Musculoskeletal Disorders of the Neck and Shoulders in Female Sewing Machine Operators: Prevalence, Incidence and Prognosis. Occup. Environ. Med. 2000 Aug; 57(8): 528-34.

KILBON, A. Repetitive Work of the Upper Extremity - part II: the Scienfsific Basis (Knowledge/Base) for the Guide. International Journal of Industrial Ergonomics, 14:54-86, 1994.

LAVILLE, A. Ergonomia. São Paulo: E.P.U. EDUSP, 1977.

MACIEL, R. H. Ergonomia e Lesões por Esforços Repetitivos. In: W. Codo \& M. C. Almeida. LER-Lesões por Esforços Repetitivos. São Paulo: Vozes, 1995.

McAtamney, L. \& CORLETT, E. N. Reducing the Risks of Work Related Upper Limb Desords: A Guide and Methods. The Institute for Occupational Ergonomics, University of Nothingham, 1992.

MONT'ALVÃO, C. R. A. Trabalho na Posição Semi-Sentada. Anais do Segundo En- contro Carioca de Ergonomia, Informatização, Automação: Sistemas, Produtos e Programas, 1994; 2: 267-274.

NAG, A., DESAl, H. \& NAG, K. Work Stress of Women in Sewing Machine Operation. J. HUMAN ERGOL., 1992; 21: 47-55.

PUNNET, L., ROBINS, J. M., WEGMAN, D. H. \& KEYSERLING, W. M. Soft Tissue Disorders in the Upper Limbs of Female Garment Workers. Scand. J. Work Environ. Health, 1985 dec; 11 (6): 417-25.

QUEIRÓZ, M. F. F. Estudo Comparativo de Dois Postos de Trabalho na Indústria Automática e na Indústria Manual do Vidro. Dissertação de Mestrado apresentada ao Departamento de Saúde Ambiental da Faculdade de Saúde Pública da Universidade de São Pulo. São Paulo, 1998.

RIBEIRO, H. P. \& LACAZ, F. A. C. De que Adoecem e Morrem os Trabalhadores. Diesat (Departamento Intersindical de Estudos e Pesquisas de Saúde e dos Ambientes de Trabalho). São Paulo, 1984. 130-131.

SILVERSTEIN, B., FINE, L.J. \& ARMSTRONG, T. J. Hand Wrist Cumulative Trauma Disoders in Industry. British Journal of Industrial Medicine, 43: 779-784, 1986.

Occupational Factors and Carpal Tunnel Syndrome. American Journal of Industrial Medicine, 11: 343-358, 1987. 